\section{Case Reports in Nephrology and Dialysis}

Case Rep Nephrol Dial 2020;10:130-138

DOI: 10.1159/000508806

Published online: October 15, 2020

(C) 2020 The Author(s)

Published by S. Karger AG, Basel www.karger.com/cnd

This article is licensed under the Creative Commons Attribution-NonCommercial 4.0 International License (CC BY-NC) (http://www.karger.com/Services/OpenAccessLicense). Usage and distribution for commercial purposes requires written permission.

\title{
Clinical Results of Tenofovir Disoproxil Fumarate in a Hemodialysis Patient with Chronic Hepatitis B
}

\author{
Daiki Aomura ${ }^{a}$ baoki Tachibana ${ }^{b}$ Michiharu Komatsu ${ }^{c}$ \\ Masakazu Kobayashid \\ aDepartment of Nephrology, Shinshu University School of Medicine, Matsumoto, Japan; \\ bDepartment of Nephrology, Suwa Red Cross Hospital, Suwa, Japan; 'Department of

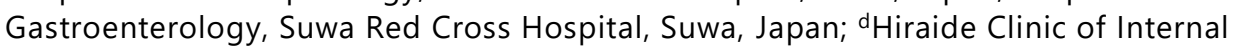 \\ Medicine and Gyneco-Obstetrics, Chino, Japan
}

\section{Keywords}

Chronic hepatitis B $\cdot$ End-stage renal disease $\cdot$ Hemodialysis $\cdot$ Nucleoside analogue $\cdot$ Tenofovir disoproxil fumarate

\begin{abstract}
A male hepatitis $B$ virus (HBV) carrier in his 40s under hemodialysis treatment exhibited chronic hepatitis (alanine aminotransferase: $41 \mathrm{IU} / \mathrm{L}, \mathrm{HBV}-\mathrm{DNA}$ : >9.1 log copies/mL). Following discontinuation of the initial treatment with pegylated interferon- $\alpha-2 a$ at 24 weeks due to adverse effects, the administration of tenofovir disoproxil fumarate (TDF) (300 mg/week) led to a rapid improvement in hepatitis markers: HBV DNA became undetectable at month 34, and seroconversion of hepatitis $B$ envelope antigen was confirmed at 45 months. No side effects were recorded during TDF treatment. TDF is a newly approved nucleoside analogue that may cause severe side effects via proximal tubular injury in patients with renal dysfunction. However, few reports have described its use in hemodialysis patients, whose anuric state may render them
\end{abstract}




\section{Case Reports in Nephrology and Dialysis}

Case Rep Nephrol Dial 2020;10:130-138

DOI: $10.1159 / 000508806$

(c) 2020 The Author(s). Published by S. Karger AG, Basel www.karger.com/cnd

Aomura et al.: Clinical Results of Tenofovir Disoproxil Fumarate in a Hemodialysis Patient with Chronic Hepatitis B

less susceptible to side effects including kidney injury. Hepatitis improved remarkably without any adverse drug reactions in the present case. TDF may therefore be considered for chronic hepatitis $B$ patients receiving hemodialysis.

(C) 2020 The Author(s)

Published by S. Karger AG, Basel

\section{Introduction}

The prevalence of hepatitis B surface antigen (HBsAg) among hemodialysis (HD) patients is much higher than in the general Japanese population [1]. Furthermore, hepatitis B virus (HBV) infection in HD patients presents a distinct clinical dilemma in view of the effects of immunosuppressive effect of renal failure, susceptibility to de novo infection, and long-term implications on morbidity and mortality [2]. However, evidence on the clinical course of patients with HBV on HD is limited, and the clinical effects of nucleoside analogues in such patients are poorly understood.

Tenofovir disoproxil fumarate (TDF) is a newly approved nucleoside analogue that is recommended as a first-line drug for the treatment of chronic hepatitis B (CHB) by the majority of worldwide guidelines in light of its antiviral potency, available safety data, and high genetic barrier to drug resistance $[3,4]$. On the other hand, TDF may cause severe side effects, including renal function impairment, and its dosage requires adjustment according to renal state [5].

As the prescription of TDF for renal dysfunction patients is generally avoided, there are few case reports on its use in HD patients with CHB. We herein describe the clinical outcome of a patient with CHB on HD who was treated successfully with TDF without any adverse events.

\section{Case Presentation}

A male patient in his 40s had been receiving regular HD for 22 years due to renal failure and chronic nephritis discovered during elementary school. He had been identified as a nonsymptomatic HBV carrier at the initiation of HD, and his serum hepatitis markers were carefully monitored every month thereafter. Approximately 20 years after HD initiation, his serum alanine aminotransferase (ALT) and $\alpha$-fetoprotein (AFP) levels began to elevate. He was referred to our gastroenterology department under suspicion of CHB. His vital signs were normal, and physical examination detected no abnormalities such as signs of anemia, jaundice, hepatomegaly, or splenomegaly. He had an arterio-venous fistula in his left forearm. He was taking clonazepam and phenytoin for epilepsy in addition to a sodium ferrous citrate, precipitated calcium carbonate, cinacalcet hydrochloride, lanthanum carbonate hydrate, and liver hydrolysate preparation. Calcitriol, a mixture of monoammonium glycyrrhizinate, glycine, and L-cysteine hydrochloride hydrate were injected at every HD treatment. Although his mother and younger sister were also HBV carriers, there was no other remarkable family history of kidney disease or otherwise. He did not drink, smoke, or use illegal drugs. Blood tests showed mild elevation of hepatobiliary enzymes (aspartate transaminase [AST]: 39 IU/L, ALT: 38 IU/L, alkaline phosphatase: $318 \mathrm{IU} / \mathrm{L}, \gamma$-glutamyl transpeptidase: $302 \mathrm{IU} / \mathrm{L}$ ) and relatively normal hepatic reserve (platelet count: $11.8 \times 10^{4} / \mu \mathrm{L}$, prothrombin time: $113 \%$, albumin: 3.2 


\section{Case Reports in Nephrology and Dialysis}

Case Rep Nephrol Dial 2020;10:130-138

DOI: $10.1159 / 000508806$

(c) 2020 The Author(s). Published by S. Karger AG, Basel www.karger.com/cnd

Aomura et al.: Clinical Results of Tenofovir Disoproxil Fumarate in a Hemodialysis Patient with Chronic Hepatitis B

g/dL, total bilirubin: $0.33 \mathrm{mg} / \mathrm{dL}$ ) (Table 1). Regarding indicators of liver cancer, although AFP was elevated, lectin-reactive AFP and protein induced by vitamin $\mathrm{K}$ absence or antagonist-II level was normal. Concerning serological markers of HBV, HBsAg and HB envelope antigen ( $\mathrm{HBeAg}$ ) were positive, $\mathrm{HB}$ envelope antibody was negative, $\mathrm{HBV}$ genotype was $\mathrm{C}$, and $\mathrm{HBV}$ DNA level was more than 9.1 log copies/mL. HBsAg was measured by the chemiluminescent enzyme immunoassay method (CLEIA) on a LUMIPULSE II device (Fujirebio, Tokyo, Japan). Urine tests were not performed due to his anuria. Electrocardiography and a chest X-ray revealed no abnormalities. Ultrasound echography showed signs of mild liver fibrosis, including a blunted edge, irregular surface, coarse texture, and splenomegaly (Fig. 1). Computed tomography (CT) disclosed mild atrophy of the right liver lobe and hypertrophy of left liver lobe, with no signs of liver cirrhosis or liver cancer (Fig. 2). We diagnosed CHB and started the patient on antiviral therapy. According to established guidelines, we first administered pegylated interferon (Peg-IFN)- $\alpha-2 \mathrm{a}(90 \mu \mathrm{g} /$ week) [4]. However, his biochemical and serological markers of CHB did not improve, and the treatment was discontinued at 24 weeks due to cytopenia, fever, and other adverse effects. No serum ALT level flares occurred during or after the treatment. We subsequently prescribed oral TDF (300 mg/week). The patient's hepatitis markers, including ALT, AFP, and HBV DNA, all rapidly improved. HBV DNA became undetectable at month 34, and seroconversion of HBeAg was confirmed at 45 months (Fig. 3). The titer of HBsAg remained constant at approximately 2,000 C.O.I. No side effects were recorded. Serum levels of ALT and HBV DNA have remained stable at 63 months of TDF treatment.

\section{Discussion}

The prevalence of HBsAg is much higher in HD patients than in the general population in Japan ( 2.6 vs. $0.6 \%$ ). The reasons for this may include susceptibility of becoming a chronic carrier due to an immunosuppressed state in addition to a higher risk of HBV exposure from staff error during medical procedures as well as exposure to blood via dialysis instruments and contaminated equipment [1]. HD patients with HBV are also faced with the risk of the immunosuppressive effect of renal failure, de novo infection and nosocomial transmission, long-term morbidity and mortality, and changes in the clinical course after kidney transplantation [2].

Among non-HD patients, the decision to initiate antiviral therapy is primarily based on ALT and HBV DNA levels [3, 4]. However, patients receiving HD are known to exhibit much lower serum transaminase levels than those not undergoing HD due to a deficiency in pyridoxal-5'-phosphate, a transaminase synthesis coenzyme [6]. In the present case, although serum transaminase levels were not remarkably high (AST: 39 IU/L and ALT: 38 IU/L), they were much higher than the average levels of patients with HD (AST: 9.2 \pm 2.4 IU/L and ALT: $7.4 \pm 1.7 \mathrm{IU} / \mathrm{L}$ ] [7], implying that our patient's serum transaminase levels were strongly elevated by CHB even under suppression by HD. Furthermore, his serum AFP level was very high in spite of no tumor signs on CT. Considering his normal level of serum lectin-reactive AFP and the decrease in serum AFP with CHB improvement by TDF, the high serum AFP was believed to have been caused not by hepatocellular carcinoma but by severe hepatitis. Although the initiation criteria of antiviral therapy for HD patients are uncertain, treatment was initiated in 


\section{Case Reports in Nephrology and Dialysis}

Case Rep Nephrol Dial 2020;10:130-138

DOI: 10.1159/000508806

(c) 2020 The Author(s). Published by S. Karger AG, Basel www.karger.com/cnd

Aomura et al.: Clinical Results of Tenofovir Disoproxil Fumarate in a Hemodialysis Patient with Chronic Hepatitis B

this case because of continuously high ALT, HBV DNA, and AFP along with a younger age and higher possibility of renal transplantation.

According to established guidelines, he was first administered Peg-IFN [4]. However, the treatment did not improve hepatitis markers and was discontinued after 24 weeks due to adverse effects. As nucleoside analogues are recommended for patients who fail or are unsuitable for Peg-IFN, we selected the nucleoside analogue TDF next. The clinical effects of nucleoside analogues on HD patients with CHB are relatively unknown, with only a few cases of lamivudine described in the literature [8]. Furthermore, as most CHB patients who are treated with nucleoside analogues require long-term treatment, one of the greatest challenges is maintaining effective viral suppression without resistance mutations. The selection of drugresistant variants after prolonged treatment with lamivudine is a major limitation. During the consideration of nucleoside analogues in this case, the first choice for non-HD patients with CHB was either entecavir (ETV) or TDF according to Japanese guidelines [4]. Both drugs show potent antiviral activity and a low rate of drug resistance. However, TDF may impart greater serological improvements in HBeAg-positive, high HBV DNA patients [9]. There have also been no confirmed reports of resistance selection during TDF treatment for HBV to date, although ETV caused resistance in $1.2 \%$ of the cases for 5 years in one study [10]. Moreover, TDF exhibits strong efficacy against variants resistant to other nucleoside analogues, including ETV [11]. Regarding the present case, the risk of hepatocellular carcinoma was very high in view of his elevated HBsAg titer, HBeAg positivity, and high HBV DNA. We also had to manage the risk of resistant variants since he would be taking nucleoside analogues for decades. Accordingly, TDF appeared more suitable than ETV as treatment.

TDF is generally avoided in patients with renal dysfunction due to possible impairments in renal performance, with features of proximal tubular injury that include Fanconi syndrome, isolated hypophosphatemia, and decreased bone mineral density (BMD) [3, 12]. TDF is eliminated in an unaltered state in the urine by a combination of glomerular filtration and proximal tubular secretion. Thirty percent of the drug is actively transported into renal proximal tubule cells by organic anion transporters in the basolateral membrane, and the drug is subsequently secreted into the tubular lumen by apical membrane transporters. Interaction with these transporters by agents or renal dysfunction may cause excessive entry or reduced outflow of the drug and lead to intracellular accumulation. Excess TDF inhibits mitochondrial DNA polymerase $\gamma$ and promotes proximal tubular injury, which may result in the reduction of renal blood flow and Fanconi syndrome and ensuing renal dysfunction, hypophosphatemia, and low BMD due to hypophosphatemia [5]. Although early randomized clinical trials have supported the renal safety of TDF, later case reports and observational studies corroborate the notion of TDF nephrotoxicity on for proximal tubular cells. Those conflicting results may be explained by the clinical trials having strict inclusion and exclusion criteria. In contrast, patients in routine clinical practice have other conditions, medications, and backgrounds that may predispose them to TDF nephrotoxicity [13]. For subjects receiving thrice-weekly, 4-h maintenance HD sessions, TDF of $300 \mathrm{mg}$ administered every 7 days after a HD session is recommended [14]. However, this indication is based on a limited number of patients having human immunodeficiency virus infection; the efficacy and safety of TDF for HD patients with HBV remains unknown [15]. Considering the mechanism of adverse effects by TDF via proximal tubular injury, it is unlikely that TDF causes severe side effects in such anuric patients as in the present case. Indeed, anuric patients receiving HD do not suffer from electrolyte abnormalities via 


\section{Case Reports in Nephrology and Dialysis}

Case Rep Nephrol Dial 2020;10:130-138

DOI: $10.1159 / 000508806$

(c) 2020 The Author(s). Published by S. Karger AG, Basel www.karger.com/cnd

Aomura et al.: Clinical Results of Tenofovir Disoproxil Fumarate in a Hemodialysis Patient with Chronic Hepatitis B

proximal tubular dysfunction and worsening of renal function, and there are no reports to date on adverse TDF drug reactions in HD patients. Low BMD is also thought to be caused via proximal tubular injury. The excretion of serum phosphate into the urine plays a key role in bone metabolism, and it is known that continuous overexcretion of phosphate collapses bone metabolism homeostasis and decreases BMD in the long term [16]. Most patients with low BMD by TDF were complicated with Fanconi syndrome and hypophosphatemia [17], for which high urinary phosphate excretion was reportedly an important risk factor [18]. Based on these facts, low BMD by TDF presumably arises from proximal tubular injury, overexcretion of phosphate, and hypophosphatemia [16]. Furthermore, low BMD by TDF is improved by calcitriol injection and the discontinuation of TDF [19], and patients receiving HD are checked for aberrant serum phosphate and bone turnover marker levels much more frequently than non-HD patients. Our patient was routinely injected with calcitriol prior to initiating TDF, and serum phosphate, intact parathyroid hormone, and other bone turnover markers were well controlled both before and after TDF commencement. In this way, HD patients may be likely treated earlier, or even pre-treated, for possible side effects arising from TDF. Although reports on TDF usage for HD patients are extremely limited, it appears that TDF has a low risk of severe side effects in anuric patients.

In this case, we selected TDF, considering his HBeAg positivity, high HBV DNA, anuria and regular HD. TDF produced remarkable improvements in serological markers of CHB without adverse effects. Although more cases and discussion are needed, TDF may be considered a preferable choice for patients with CHB on HD.

In conclusion, TDF may be suitable for CHB patients on HD.

\section{Statement of Ethics}

The present case report adhered to the Declaration of Helsinki. Written informed consent for publication (including images) was obtained from the patient.

\section{Conflict of Interest Statement}

The authors declare no conflicts of interest.

\section{Funding Sources}

The authors received no specific funding for this work.

\section{Author Contributions}

Daiki Aomura drafted the article. Naoki Tachibana and Michiharu Komatsu revised the article critically for important intellectual content. Masakazu Kobayashi revised the article 


\section{Case Reports in Nephrology and Dialysis}

Case Rep Nephrol Dial 2020;10:130-138

(C) 2020 The Author(s). Published by S. Karger AG, Basel www.karger.com/cnd

Aomura et al.: Clinical Results of Tenofovir Disoproxil Fumarate in a Hemodialysis Patient with Chronic Hepatitis B

critically for important intellectual content and gave final approval of the version to be submitted.

\section{References}

1 Katayama K, Sato T, Do SH, Yamada H, Tabuchi A, Komiya Y, et al. Hepatitis B virus infection in hemodialysis patients in Japan: Prevalence, incidence and occult hepatitis B virus infection. Hepatol Res. 2015 Dec;45(12):1211-9.

2 Elbedewy T, Elshweikh S, Baiomy N. Prevalence and significance of hepatitis-B core antibodies among hepatitis B surface antigen-negative Egyptian patients on hemodialysis in Al-Gharbia governorate. Tanta Med J. 2016 Apr;44(2):33-8.

3 Terrault NA, Lok AS, McMahon BJ, Chang KM, Hwang JP, Jonas MM, et al. Update on prevention, diagnosis, and treatment of chronic hepatitis B: AASLD 2018 hepatitis B guidance. Hepatology. 2018 Apr;67(4):156099.

4 JSH Guidelines for the Management of Hepatitis B Virus Infection. Hepatol Res. 2014 Jan;44 Suppl S1:1-58.

5 Fernandez-Fernandez B, Montoya-Ferrer A, Sanz AB, Sanchez-Niño MD, Izquierdo MC, Poveda J, et al. Tenofovir nephrotoxicity: 2011 update. Aids Res Treat. 2011;2011:354908.

6 Ono K, Ono T, Matsumata T. The pathogenesis of decreased aspartate aminotransferase and alanine aminotransferase activity in the plasma of hemodialysis patients: the role of vitamin B6 deficiency. Clin Nephrol. 1995 Jun;43(6):405-8.

7 Yasuda K, Okuda K, Endo N, Ishiwatari Y, Ikeda R, Hayashi H, et al. Hypoaminotransferasemia in patients undergoing long-term hemodialysis: clinical and biochemical appraisal. Gastroenterology. 1995 Oct;109(4):1295-300.

8 Schmilovitz-Weiss H, Melzer E, Tur-Kaspa R, Ben-Ari Z. Excellent outcome of Lamivudine treatment in patients with chronic renal failure and hepatitis B virus infection. J Clin Gastroenterol. 2003 Jul;37(1):64-7.

9 Park JW, Kwak KM, Kim SE, Jang MK, Suk KT, Kim DJ, et al. Comparison of the long-term efficacy between entecavir and tenofovir in treatment- naïve chronic hepatitis B patients. BMC Gastroenterol. 2017 Mar;17(1):39.

10 Osborn M. Safety and efficacy of entecavir for the treatment of chronic hepatitis B. Infect Drug Resist. 2011;4:55-64.

11 Kumada H, Koike K, Suyama K, Ito H, Itoh H, Sugiura W. Efficacy and safety of tenofovir disoproxil fumarate rescue therapy for chronic hepatitis B patients who failed other nucleos(t)ide analogs. Hepatol Res. 2017 Sep;47(10):1032-41.

12 Conti F, Vitale G, Cursaro C, Bernardi M, Andreone P. Tenofovir-induced Fanconi syndrome in a patient with chronic hepatitis B monoinfection. Ann Hepatol. 2016 Mar-Apr;15(2):273-6.

13 Cooper RD, Wiebe N, Smith N, Keiser P, Naicker S, Tonelli M. Systematic review and meta-analysis: renal safety of tenofovir disoproxil fumarate in HIV-infected patients. Clin Infect Dis. 2010 Sep;51(5):496-505.

14 Kearney BP, Yale K, Shah J, Zhong L, Flaherty JF. Pharmacokinetics and dosing recommendations of tenofovir disoproxil fumarate in hepatic or renal impairment. Clin Pharmacokinet. 2006;45(11):1115-24.

15 Chan L, Asriel B, Eaton EF, Wyatt CM. Potential kidney toxicity from the antiviral drug tenofovir: new indications, new formulations, and a new prodrug. Curr Opin Nephrol Hypertens. 2018 Mar;27(2):102-12.

16 Casado JL. Renal and Bone Toxicity with the Use of Tenofovir: understanding at the End. AIDS Rev. 2016 Apr-Jun;18(2):59-68.

17 Mateo L, Holgado S, Mariñoso ML, Pérez-Andrés R, Bonjoch A, Romeu J, et al. Hypophosphatemic osteomalacia induced by tenofovir in HIV-infected patients. Clin Rheumatol. 2016 May;35(5):1271-9.

18 Casado JL, Santiuste C, Vazquez M, Bañón S, Rosillo M, Gomez A, et al. Bone mineral density decline according to renal tubular dysfunction and phosphaturia in tenofovir-exposed HIV-infected patients. AIDS. 2016 Jun;30(9):1423-31.

19 Overton ET, Chan ES, Brown TT, Tebas P, McComsey GA, Melbourne KM, et al. Vitamin D and Calcium Attenuate Bone Loss With Antiretroviral Therapy Initiation: A Randomized Trial. Ann Intern Med. 2015 Jun;162(12):815-24. 
Case Reports in Nephrology and Dialysis

\section{Case Rep Nephrol Dial 2020;10:130-138}

DOI: $10.1159 / 000508806$

(c) 2020 The Author(s). Published by S. Karger AG, Basel www.karger.com/cnd

Aomura et al.: Clinical Results of Tenofovir Disoproxil Fumarate in a Hemodialysis Patient with Chronic Hepatitis B
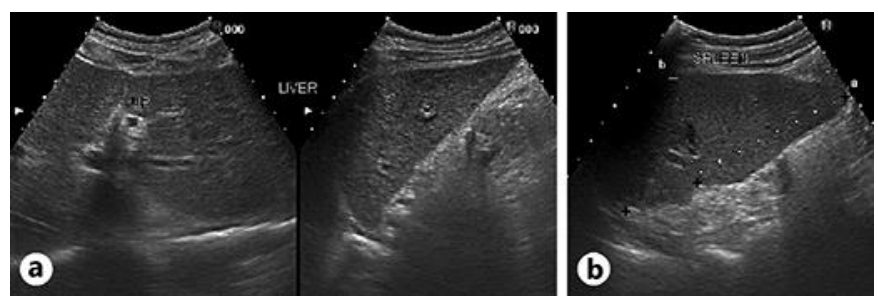

Fig. 1. Abdominal ultrasonography showing signs of mild liver fibrosis including blunted edge, irregular surface, coarse texture (a), and splenomegaly (b).

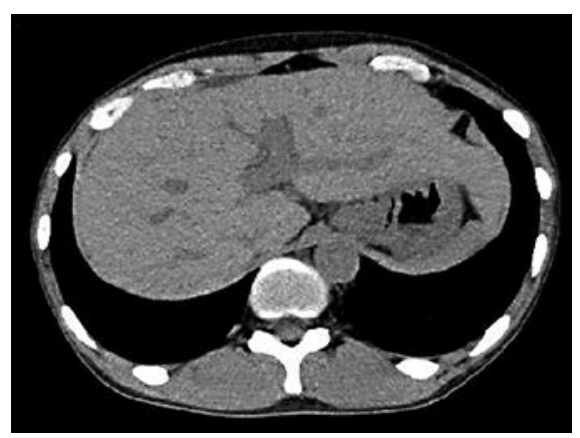

Fig. 2. Abdominal CT revealing mild atrophy of the right lobe of the liver and hypertrophy of the left lobe of the liver. 
Case Reports in Nephrology and Dialysis
Case Rep Nephrol Dial 2020;10:130-138

(C) 2020 The Author(s). Published by S. Karger AG, Basel www.karger.com/cnd

Aomura et al.: Clinical Results of Tenofovir Disoproxil Fumarate in a Hemodialysis Patient with Chronic Hepatitis B

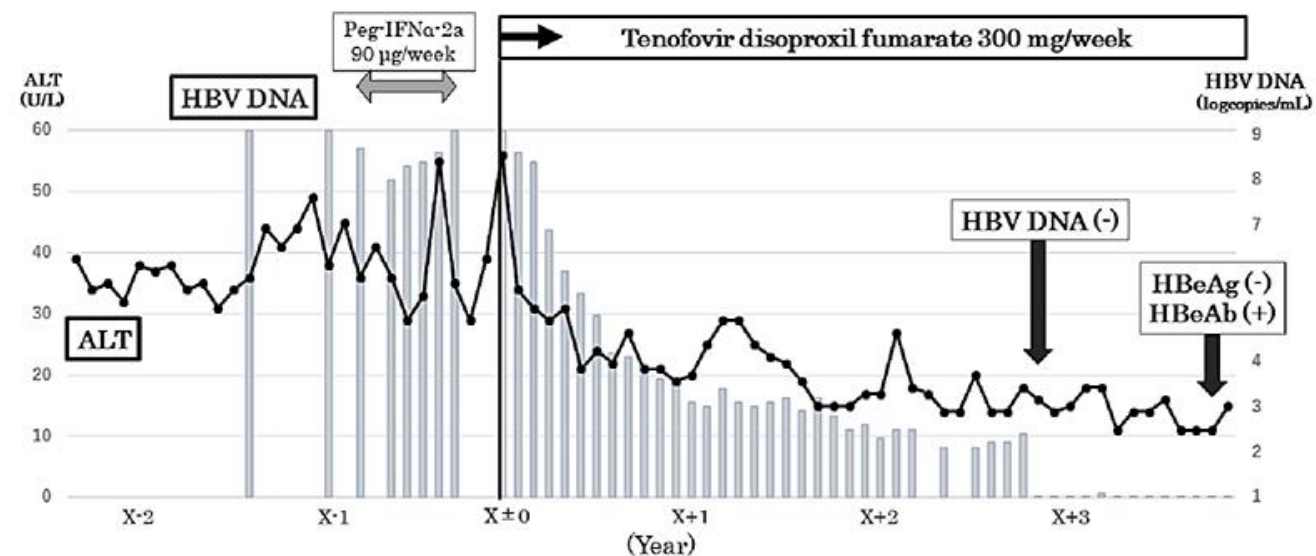

ALT; alanine aminotransferase, HBV DNA; hepatitis B virus deoxyribo nucleic acid, HBeAb; hepatitis B envelope antibody, $\mathrm{HBeAg}$; hepatitis B envelope antigen, Peg-IFNa-2a; pegylated interferon' $\alpha-2 \mathrm{a}$,

Fig. 3. Initial treatment with pegylated interferon- $\alpha-2$ a was discontinued after 24 weeks due to adverse effects. Subsequent administration of TDF (300 $\mathrm{mg} /$ week) resulted in a rapid decrease in ALT and HBV DNA levels. HBV DNA became undetectable at month $\mathrm{X}+34$, and seroconversion of $\mathrm{HBeAg}$ was achieved at month $\mathrm{X}+45$. 


\section{Case Reports in Nephrology and Dialysis}

Table 1. Laboratory data

\begin{tabular}{|c|c|c|c|}
\hline & Patient values & Normal values & Unit \\
\hline \multicolumn{4}{|l|}{ Hematological analysis } \\
\hline White blood cells & $5.04 \times 10^{3}$ & $2.97-9.13 \times 10^{3}$ & $/ \mu \mathrm{L}$ \\
\hline Hemoglobin & 11.9 & $12.9-17.4$ & $\mathrm{~g} / \mathrm{dL}$ \\
\hline Platelets & $11.8 \times 10^{4}$ & $14.3-33.3 \times 10^{4}$ & $/ \mu \mathrm{L}$ \\
\hline \multicolumn{4}{|l|}{ Coagulation } \\
\hline Fibrinogen & 383 & $180-350$ & $\mathrm{dL}$ \\
\hline Prothrombin time & 117 & $70-130$ & $\%$ \\
\hline Activated partial thromboplastin time & 26.3 & $23.0-38.0$ & s \\
\hline \multicolumn{4}{|l|}{ Biochemistry } \\
\hline Albumin & 3.2 & $4.1-5.1$ & $\mathrm{~g} / \mathrm{dL}$ \\
\hline AST & 39 & $13-30$ & $\mathrm{U} / \mathrm{L}$ \\
\hline ALT & 38 & $7-23$ & $\mathrm{U} / \mathrm{L}$ \\
\hline Alkaline phosphatase & 318 & $106-322$ & $\mathrm{U} / \mathrm{L}$ \\
\hline$\gamma$-glutamyl transpeptidase & 302 & $9-32$ & $\mathrm{U} / \mathrm{L}$ \\
\hline Total bilirubin & 0.33 & $0.4-1.5$ & $\mathrm{mg} / \mathrm{dL}$ \\
\hline Blood urea nitrogen & 87.8 & $8-20$ & $\mathrm{mg} / \mathrm{dL}$ \\
\hline Creatinine & 15.03 & $0.46-0.79$ & $\mathrm{mg} / \mathrm{dL}$ \\
\hline Calcium & 10.1 & $8.8-10.1$ & $\mathrm{mg} / \mathrm{dL}$ \\
\hline Phosphate & 4.1 & $2.7-4.6$ & $\mathrm{mg} / \mathrm{dL}$ \\
\hline Intact parathyroid hormone & 113 & $10-65$ & $\mathrm{pg} / \mathrm{mL}$ \\
\hline \multicolumn{4}{|l|}{ Serology } \\
\hline C-reactive protein & 0.45 & $<0.14$ & $\mathrm{mg} / \mathrm{dL}$ \\
\hline \multicolumn{4}{|l|}{ Viral markers } \\
\hline HBsAg & $2,000.0$ & $<0.9$ & C.O.I. \\
\hline HBsAb & 0.1 & $<0.9$ & $\mathrm{mIU} / \mathrm{mL}$ \\
\hline HBeAg & 469 & $<0.9$ & $\mathrm{~S} / \mathrm{CO}$ \\
\hline $\mathrm{HBeAb}$ & $<35$ & $<50$ & $\%$ \\
\hline HBV DNA & $>9.1$ & - & $\log$ copies $/ \mathrm{mL}$ \\
\hline Genotype & $\mathrm{C}$ & & \\
\hline HBC antibody & 0.1 & $<0.9$ & C.O.I. \\
\hline \multicolumn{4}{|l|}{ Tumor markers } \\
\hline AFP & 252 & $<20$ & $\mathrm{ng} / \mathrm{dL}$ \\
\hline Lectin-reactive AFP & 5.8 & $<10$ & $\%$ \\
\hline Protein induced by vitamin $\mathrm{K}$ absence or antagonist-II & 21 & $<40$ & $\mathrm{mAU} / \mathrm{mL}$ \\
\hline
\end{tabular}

